\title{
Cleft Lip and Palate: The Unsolicited Streak
}

\author{
Chritson $^{1}$, Sibgatullah ${ }^{2}$, Jayesh ${ }^{3}$, Karthik D Yadav ${ }^{4 *}$ and Aklanta Kumar Gogoi ${ }^{5}$ \\ ${ }^{1}$ Master of Dental Surgery, Department of Cons \& Endo, Dental Enclave, Bangalore. \\ ${ }^{2}$ Master of Dental Surgery, Department of oral \& maxillofacial surgery, Advanced Dental Hospital, India \\ ${ }^{3}$ Master of Dental Surgery, Assistant Professor, Department of Oral \& Maxillofacial Surgery, Hazaribagh College of Dental Sciences, India \\ ${ }^{4}$ Master of Dental surgery, Assistant Professor, Department of oral medicine and radiology, KGF College of Dental Sciences, India \\ ${ }^{5}$ Department of oral \& maxillofacial surgery, Dental Enclave, India
}

*Corresponding author: Karthik D Yadav, Master of Dental Surgery, Assistant Professor, Department of Oral Medicine and Radiology,

Dental Enclave, India

\begin{abstract}
Cleft palate is the third most common congenital deformity subsequent to clubfoot and the cleft lip. It may be either unilateral or bilateral and is either complete or incomplete. A multidisciplinary team approach is important to accomplish the various façades pretentiously observed by orofacial cleft. The optimum time of surgical repair is based on the surgeon's preference, anesthetic risks, co-morbid congenital anomalies, and the apparent psychological impact on the family. Most surgeons repair the cleft lip around 10-12 weeks of age. Cleft palate and lip need early care and attention with a long-term follow-up which requires a team approach involving many specialties.
\end{abstract}

\section{Introduction}

Cleft palate is the third most common congenital deformity subsequent to clubfoot and the cleft lip [1]. It is seen as anatomical changes which involves the upper lip, nose, and the palate [2]. It represents roughly about $65 \%$ of the malformations of the craniofacial section [3]. In this, unilateral cleft lip and palate have been found to have the majority at $46 \%$, followed by isolated cleft palate accounting for $33 \%$ of cases. These two being the most common diagnosis among the cleft lip and palate population followed by the others [1].Cleft lips show racial unpredictability, with the highest incidence seen among Asian and Native Americans (1:450 live births) and the lowest incidence seen in the African Americans (1:2,000 live births) [4]. Isolated cleft palate is seen more commonly in females (57\%) than in males (43\%), with gender differences attributable to the differences in the timing of the embryologic development [4]. About $50 \%$ of the isolated cleft palates are found to be in relation with a malformation syndrome, in comparison $15 \%$ of combined cleft lip and palate patients without any syndrome [5]. Velocardiofacial syndrome (VCFS) has been found to be the most common syndrome, which is associated with isolated cleft palate [6]. Other etiological factors associated with cleft palate are gestational exposures to alcohol, cigarette smoking, steroids, rubella, anticonvulsants, retinoids, advanced paternal age, folate deficiency and hypoxia [7-9]. An affected parent having a child with a cleft palate is $7 \%$. If one sibling has a palatal cleft with no parental clefts, then future siblings have $2 \%$ jeopardy of developing a cleft. That risk upsurges to about $17 \%$ if there is one affected sibling and a parent with a cleft [10].

\section{Anatomy}

The palate is divided into the primary and the secondary palate. The primary palate comprises of the alveolar arch and secondary palate comprises of the hard and the soft palate. The hard palate is formed by the palatine processes of the maxillae and by the horizontal lamina of the palatine bones. It is covered by oral and nasal mucosa [11].

\section{Cleft classification}

A cleft palate may be either unilateral or bilateral and is either complete or incomplete [12]. The Veau System classifies orofacial 
clefting into four classes by whether the secondary and/or primary palates are affected and by laterality [13].

a) Veau Class I: Incomplete cleft, soft palate only (no unilateral/ bilateral designation)

b) Veau Class II: Hard and soft palate, secondary palate only (no unilateral/bilateral designation)

c) Veau Class III: Complete unilateral cleft including lip (primary and secondary palates)

d) Veau Class IV: Complete bilateral cleft

\section{Clinical manifestations}

a) Cleft palate is difficulty with feeding [14].

b) Velopharyngeal Insufficiency.

c) Speech distortion especially is the consonant /s/ [15].

d) Hyper-nasality-the perception of excessive nasal resonance during the production of vowels.16

e) Reduced loudness.

f) Monotone quality.

g) Strangled voice quality - an attempt to be non-nasal in the presence of VPI.

\section{Management}

A multidisciplinary team approach is important to accomplish the various façades pretentiously observed by orofacial clefting. The reconstructive surgeon, otolaryngologists, dentists, orthodontists, speech pathologists, audiologists, geneticists, psychiatrists, maxillofacial surgeons, prosthodontists, and social workers form the most important crucial members of the team treating the patients [17]. The procedure of cleft palate repair has been suggested and gained popularity over many years and is not a one-day ideology. These techniques have undergone numerous modifications that are practiced today. The task of contemporary palatoplasty is not just the closure of the cleft palate but also is to enable optimal speech without compromising the maxillofacial growth [18]. The optimum time of surgical repair is based on the surgeon's preference, anesthetic risks, co-morbid congenital anomalies, and the apparent psychological impact on the family. Most surgeons repair the cleft lip around 10-12 weeks of age. The rule of 10's was endorsed by Wilhelmsen and Musgrave that repair of cleft lip should take place when the patient reaches the ensuing cut-offs: weight $10 \mathrm{lbs}$, hemoglobin $10 \mathrm{~g} / \mathrm{dL}$, and white blood cell count <10,000 mm3 [19]. It was Mallard who proposed the commonly used "rule of order 10" for the timing of repair stated as weight over $10 \mathrm{lbs}$, hemoglobin over $10 \mathrm{~g} / \mathrm{dL}$ and over 10 weeks [20].

A recommendation by Dallas operative protocol for treatment of cleft lip and palate cases is that at three months of age, primary unilateral cleft lip and nose should be treated and at six to nine months, palatoplasty should be performed in a single stage; At the age of five years, lower secondary cleft lip and nose; from seven to nine, cancellous bone graft from the iliac to the alveolar cleft; after full growth, orthognathic surgery; from 12 to 18, soft tissue surgery, rhinoplasty or other should be done [21]. However, in developing countries there is a significant risk of neglect of palatoplasty procedure after lip repair. Cleft palate should be initially repaired at the age of 6-9 months of age, as suggested by Agrawal et al, whereas cleft lip should be fixed three to six months after the first operation [22]. Further, all-in-one (AIO) closing procedure includes the repair of the lip, hard and soft palate within a single stage. De Mey et al. in his study has shown the AIO surgical protocol offers many benefits, such as a single anesthesia, less hospitalization, less snooping during the growth process, lower amount of scar tissue, no secondary operations, being an ideal alternative for countries that do not have a health system able to afford the costs of a multistage, multidisciplinary treatment [23]. The operative schedule plays an important role in the prognosis of patients with cleft lip and palate, so that the timing of the primary palate closure can influence the indication for orthognathic surgery. According to Broome et al. Children who had conventional repair of primary cleft palate during the first year of life need orthognathic surgery more than those who underwent repair of the soft palate at three months of age, and hard palate at six [24]. To ensure the proper development of speech, the Protocol of Marburg (Germany) establishes the closure of the soft palate at six months of age and hard palate not before 13 years of age. Likewise, the Malek operating protocol anticipates the closure of the soft palate to allow speech without compensatory mechanisms and delays the closure of the hard palate to minimize iatrogenic effects in the face [25].

Nonsurgical treatment of the cleft palate is attempted with prosthodontic devices designed to correct velopharyngeal incompetence. Indications for use of prosthodontic devices are rare and largely of historical interest. Candidates who may benefit from prosthodontic devices are those who do not want or are too high risk for surgery, those in whom surgery has failed, or patients who would benefit from better alignment of the maxillary segments prior to definitive surgery [26]. The major drawback is that the prosthesis must be realigned every 2 weeks until growth is finished. Additionally, the device may be irritating to the fragile mucosal surface, difficult to clean, and require cooperation on the child's behalf. Obturation is practical beginning at ages 3 to 4 years. The principle advantage is achieving as high or a higher rate of velopharyngeal competence than with surgery while avoiding potential surgical complications, such as restricted maxillary growth. Cleft patients are capable of normal facial skeleton development, but corrective surgical procedures are known to impair maxillary growth and may lead to midface retrusion [27]. Optimal timing of cleft palate repair must consider other medical conditions and 
speech development. Early repair has been shown to benefit speech development but may inhibit facial growth to a greater extent as transverse facial growth is not complete until 5 years of age. In the past, surgery on the palate was often delayed until maxillary growth was completed or when deciduous molars achieved proper occlusion. Recently, speech outcomes have taken precedence and as a result, most experts repair cleft palates beginning at 10 months of age [25-28]. Some advocate waiting until 2 years of age to operate on large cleft palates. Surgery on isolated soft palate clefts has been advocated as early as 3 months of age. The most common surgical techniques for repair of the soft palate are the Furlow doubleopposing Z-plasty and the intralveolar veloplasty. The bony palate is often repaired using the Von Langenbeck palatoplasty, the VeauWardill- Kilner palatoplasty, or a Bardach two-flap palatoplasty. Vomer flaps are used in conjunction with the above hard palate repairs to repair the nasal mucosa $[29,30]$. Rhinoplasty in cleft lip and nose patients can lead to the formation of inclusion cysts, which can be either epidermoid or the mucous cysts, which is based on the type of the epithelium seen [31].

In case of repair involving the patients with bilateral cleft lip and palate, a deformity in the central portion of the upper lip is seen which usually requires multiple revisions throughout childhood. The other deformities seen are the lack of redness in the midline, with relative excess laterally (whistle deformity); incompatibility of the lip vermilion color when compared with the hypoplastic prolabium vermilion; enlargement and absence of depression in the philtrum; straight lateral columns; absence or deformation of the cupid's bow and philtrum landmarks [32]. In case of secondary deformity associated with bilateral clefts, Abbe flap technique is the surgical method with the initial phase of the technique being the evaluation of bilateral cleft lip and palate and rotation of a pedicle flap of the lower lip in a defect created in the center of the upper lip. The pedicle should remain in place for two to three weeks to neovascularization and posterior section with safely. To ensure proper extension, this procedure should be performed with the premaxilla in the correct position. The cases in which the premaxilla is deficient should undergo Le Fort I surgery before the Abbe flap. In the Texas Children's Hospital, Koshy concluded that this flap is effective for replacing structural components and functional defects of the total thickness of the upper and lower lips resulting from the resection of cancer, birth defects or traumatic amputation [32]. Vertical excess of the premaxilla has been a challenge for orthodontists and surgeons according to Meazzini et al. constituting a serious cosmetic problem that does not improve spontaneously with growth [33]. Orthodontic intrusion during the growth phase offers advantages such as the use of low-intensity forces, improves the relationship between the front teeth and upper lip due to control of the premaxilla, and allows further growth of the impaired maxilla in patients with bilateral cleft. In severe cases, such as 7-8 $\mathrm{mm}$ superior bulge, orthodontics alone is not enough to achieve the intended objectives and should not be indicated because of the risk of root resorption and, considering the expected mandibular growth, the good positioning of the premaxilla is important [33]. The two most common abnormalities after primary lip repair according to Koh are the loss of the philtrum setting and the obliteration of the cupid's bow [34]. Cleft lip and palate patients are at higher risk for chronic middle ear disease, hearing loss, hypochromic anemia, and hypoproteinemia, [35] particularly individuals from lower social classes. Patients undergoing Millard lip repair are at increased risk for development of cholesteatoma and tympanic membrane perforation. However, the type of palatoplasty and age did not influence the otologic and audiologic indicators of children of 5-6 years with unilateral cleft [36].

\section{Conclusion}

Cleft palate and lip need early care and attention with a longterm follow-up which requires a team approach involving many specialties. However, there are many complications associated with the cleft palate and lip, therefore a systematic approach is, was and always will be the need of the hour.

\section{References}

1. Strong EB, Buckmiller LM (2001) Management of the cleft palate. Facial Plast Surg Clin North Am 9(1): 15-25.

2. Buzzo CL (2010) Surgical treatment of cleft lip using the Goteborg technique: 7-year follow-up. Rev Bras Cir Plast 25(2): 251-259.

3. Gorlin R, Hennekam R (2001) Syndromes of the head and neck. $4^{\text {th }}$ (Ed.), Oxford University Press, New York, UK p. 1-13.

4. Vanderas AP (1987) Incidence of cleft lip, cleft palate, and cleft lip and palate among races: a review. Cleft Palate J 24(3): 216-225.

5. Shprintzen RJ, Siegel-Sadewitz VL, Amato J, Goldberg RB (1985) Anomalies associated with cleft lip, cleft palate, or both. Am J Med Genet 20(4): 585-595.

6. Fraser FC (1970) The genetics of cleft lip and cleft palate. Am J Hum Genet 22(3): 336-352.

7. Lorente C, Cordier S, Goujard J (2000) Occupational Exposure and Congenital Malformation Working Group. Tobacco and alcohol use during pregnancy and risk of oral clefts. Am J Public Health 90(3): 415419.

8. Källén B (2003) Maternal drug use and infant cleft lip/palate with special reference to corticoids. Cleft Palate Craniofac J 40(6): 624-628.

9. Savitz DA, Schwingl PJ, Keels MA (1991) Influence of paternal age, smoking, and alcohol consumption on congenital anomalies. Teratology 44(4): 429-440

10. Matthews MS, Cohen M, Viglione M, Brown AS (1998) Prenatal counseling for cleft lip and palate. Plast Reconstr Surg 101(1): 1-5.

11. Marks MW, Marks C (1997) Cleft lip and palate. In: Fundamentals of Plastic Surgery. Philadelphia, PA: Saunders, p. 156.

12. Sperber GH (2002) Formation of the primary palate and palatogenesis: closure of the secondary palate. In: Wyszynski DF, ed. Cleft Lip and Palate: From Origin to Treatment. Oxford University Press, New York, UK p. 5-24.

13. Veau V (1931) Division Palatine. Paris: Masson \& Cie. 
14. Bessell A, Hooper L, Shaw WC, Reilly S, Reid J, et al. (2011) Feeding interventions for growth and development in infants with cleft lip, cleft palate or cleft lip and palate. Cochrane Database Syst Rev (2): CD003315.

15. Wyatt R, Sell D, Russell J, Harding A, Harland K, et al. (1996) Cleft palate speech dissected: a review of current knowledge and analysis. Br J Plast Surg 49(3): 143-149.

16. Priester GH, Goorhuis-Brouwer SM (2008) Speech and language development in toddlers with and without cleft palate. Int J Pediatr Otorhinolaryngol72(6): 801-806.

17. van Aalst JA, Kolappa KK, Sadove M (2008) MOC-PSSM CME article: Non syndromic cleft palate. Plast Reconstr Surg 121(1 Suppl): 1-14.

18. Leow AM, Lo LJ (2008) Palatoplasty: evolution and controversies. Chang Gung Med J31(4): 335-345.

19. Wilhelmsen HR, Musgrave RH (1966) Complications of cleft lip surgery. Cleft Palate J 3: 223-231.

20. Millard DR (1957) A primary camouflage of the unilateral hare look. In: Skoog T, Ivy RH, editors. Transactions of the International Society of Plastic Surgeons the Williams \& Wilkins, Baltimore, USA p. 160.

21. Salyer KE (2001) Excellence in Cleft Lip and Palate Treatment. J Craniofacial Surg 12(1): 2-5.

22. Agrawal K, Panda K (2011) A modified surgical schedule for primary management of cleft lip and palate in developing countries. Cleft Palate Craniofac J 48(1): 1-8.

23. De Mey A, Franck D, Cuylits N, Swennen G, Malevez C, et al. (2009) Early one-stage repair of complete unilateral cleft lip and palate. J Craniofac Surg 20(Suppl 2): 1723-1728.

24. Broome M, Herzog G, Hohlfeld J, Roessingh AB, et al. (2010) Influence of the primary cleft palate closure on the future need for orthognathic surgery in unilateral cleft lip and palate patients. J Craniofac Surg 21(5): 1615-1618.

25. Silva Filho OG, Calvanob F, Assunção AGA, Cavassana AO (2001) Craniofacial Morphology in Children with Complete Unilateral Cleft Lip and Palate: A Comparison of Two Surgical Protocols. Angle Orthodontist 71(4): 274-284.
26. Grayson BH, Maull D (2004) Nasoalveolar molding for infants born with clefts of the lip, alveolus, and palate. Clin Plast Surg 31(2): 149-158.

27. Shetye PR (2004) Facial growth of adults with un-operated clefts. Clin Plast Surg 31(2): 361-371.

28. Rohrich RJ, Love EJ, Byrd HS, Johns DF (2000) Optimal timing of cleft palate closure. Plast Reconstr Surg106 (2): 413-421, quiz 422, discussion 423-425.

29. Salyer KE, Sng KW, Sperry EE (2006) Two-flap palatoplasty: 20-year experience and evolution of surgical technique. Plast Reconstr Surg 118(1): 193-204.

30. Sommerlad BC (2003) A technique for cleft palate repair. Plast Reconstr Surg 112(6): 1542-1548.

31. Pausch NC, Bertolini J, Alexander Hemprich A, Hierl T (2010) Inclusion Mucous Cysts of the Nose: A Late Complication After Septorhinoplasty in Two Cleft Lip Patients. Cleft Palate Craniofac J 47(6): 668-672.

32. Koshy JC, Ellsworth WA, Sharabi SE, Hatef DA, Hollier LH, et al. (2010) Bilateral Cleft Lip Revisions: The Abbe Flap. Plast Reconstr Surg 126: 221-227.

33. Meazzini M, Lematti L, Mazzoleni F, Rabbiosi D, Bozzetti A, et al. (2010) Vertical Excess of the Premaxilla in Bilateral Cleft Lip and Palate Patients: A Protocol for Treatment. J Craniofac Surg 21(2): 499-502.

34. Koh KS, Hong JP (2005) Unilateral complete cleft lip repair: orthotopic positioning of skin flaps. British J Plastic Surg 58: 147-152.

35. Millard Jr (1994) Embryonic rationale for the primary correction of classical congenital clefts of the lip and palate. Ann R Coll Surg Engl 76: 150-160.

36. Antonelli P, Jorge J, Feniman M, Piazentin-Penna S, Dutka-Souza J, et al. (2010) Otologic and audiologic outcomes with the furlow and von langenbeck with intravelar veloplasty palatoplasties in unilateral cleft lip and palate. Cleft Palate Craniofac J 48(4): 412-418.
This work is licensed under Creative Commons Attribution 4.0 License

To Submit Your Article Click Here: Submit Article

DOI: $10.32474 /$ IPDOAJ.2020.04.000198

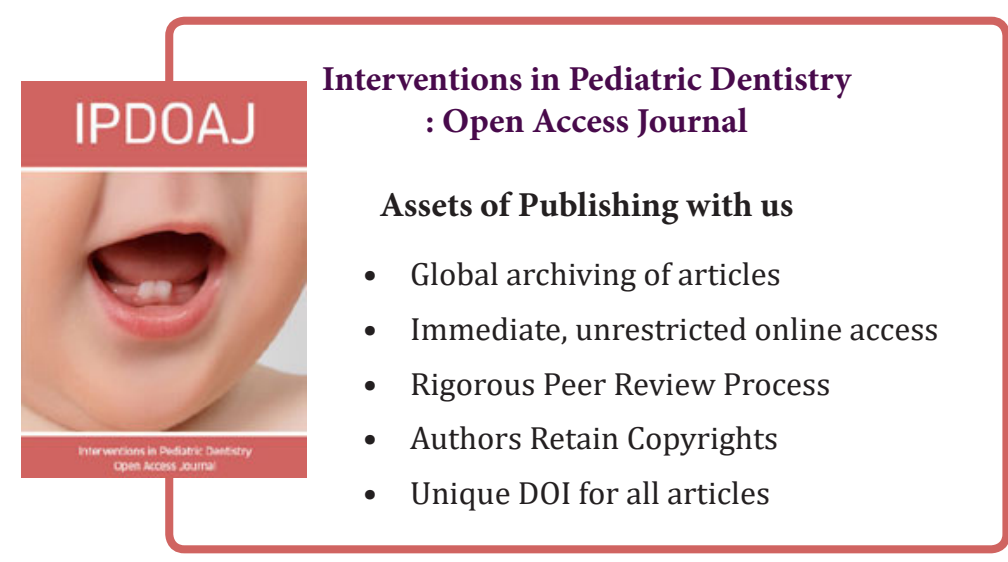

